\title{
INFORMATIZATION OF THE MODERN EDUCATIONAL SPACE OF HIGHER EDUCATION FROM THE POSITION OF THE CONSCIOUS APPROACH
}

\author{
Ekaterina Aleksandrova \\ Samara State Medical University, Russian Federation
}

\begin{abstract}
The accumulated human knowledge becomes available in electronic format. Universal access to the global network is changing modern methods of teaching, education, and management. Learners are ready to use network technologies quite consciously and intuitively. The aim of the study is to identify and design the links between the development of modern society and the higher education system via information and communication technologies. The novelty of the study lies in the identification of an informative-conscious approach in the higher education system as an independent one. The study was conducted on the basis of the application of theoretical research methods. The methodological basis of the study was conceptual approach and an appeal to the origins of modern education informatization. In the field of the conducted research, aimed at the social-philosophical analysis of pedagogical activities and education, the close causality of the development of education from the development of the modern society informatization was educed. In the higher education system was individualized informative-conscious approach, that is based on the field of information and communication technologies and has the basis of an informative identity.

Keywords: higher education, information space, information and communication technologies, content of education, informatization of modern educational space, informative-conscious approach.
\end{abstract}

\section{Introduction}

The huge amount of knowledge accumulated by mankind forces us to look for other approaches to organize the learning process. The use of modern technologies in the field of higher education creates favorable conditions for the formation of the students' personality and meets the needs of modern society. The teacher of today does not simply apply new technical means in the old education system, but operates in a new educational environment, ensures the successful functioning of education in the modern world. 
Aleksandrova, 2021. Informatization of the Modern Educational Space of Higher Education from the Position of the Conscious Approach

In the course of the study, a number of hypotheses were put forward:

- Nowadays we have a global rethinking of the role of information processes in the development of nature and society.

- The globalization of educational processes is depending on informatization.

- Conditions that satisfy the needs of any person in obtaining the necessary information have to be created.

- Modern information technologies make it possible to build an effective educational environment management system, they are relevant today for solving the problems of socio-economic development.

- $\quad$ The use of information technologies ensures a further increase in the volume of information processes and changes in the content of education.

The purpose of the study, aimed at a socio-philosophical analysis of the foundations of pedagogical activity and education, can be considered the allocation of an informative-conscious approach in the higher education system as an independent one. The object of research is explaining the reason for the existence of informative-conscious approach as a new direction in the higher education system.

The information revolution that began in the 70s of the XXth century gave an impetus to human civilization for the transition from an industrial to an information society, the society in which the most workers are engaged in the production, storage, processing and implementation of all forms of the information, especially its highest form, which is called knowledge. The author focuses on the fact that our society is no longer just informational, but information-conscious. 50 years after the beginning of the information revolution a new society has grown and the sphere of information interests for this society is simple and commonplace.

The development of modern info-communication technologies opens up new horizons and opportunities in the field of higher education. The transition to an informative-conscious level can provide a real breakthrough in the personification of the educational process, contribute to students' self-realization and overcome the costs of the mass reproductive training system. This level carries a pedagogically competent and psychologically correct application of infocommunication technologies.

Mainly theoretical research methods were used by the preparation of this study, which is due to the formulation of the research problem. Deductive logic made it possible to draw a general conclusion about the informatization of the modern educational space of higher education from the position of a conscious approach. 


\section{Literature Review}

The educational capabilities of modern information technologies (IT), like any teaching tools, are fully disclosed and implemented if they serve as an organic tool for the development of educational communications in the logic of the practice of university training due to the personal dimension. Information technologies in teaching process are rational means in the development of creative and constructive abilities of students. The inclusion of IT in the educational process affects the nature of the course of the pedagogical process.

In the author's assessment, an appeal to the origins of modern education informatization takes on an important aspect. However, we can't simply embed information technologies into the usual educational process and hope that they will revolutionize education. So, Shreider Yu.A., who was the first to propose the concept of the information environment, imphasizes the fact that the information environment doesn't work only as a conductor of information, but it has an active impacts on its participants (Shrader, 1976).

Modern info-communication technologies are introduced at virtually all levels of education. We can read about many problems of their use in modern didactics in numerous scientific publications on this subject (Babansky, 1989; Latyshev, 1995; Chernov, 2003; Melamud, 2004; Velichko, 2009).

Shutenko E.N., Derevianko Yu.P. (Shutenko \& Derevyanko, 2016) bring to our attention that it is necessary to change the concept of the educational process, into which these technologies would organically fit as a new means of teaching. The conditions created with their help should contribute to the formation of holistic thinking and worldview of the students, orient them towards the search for systemic connections and patterns.

Having analyzed above-mentioned, we can state that the huge amount of knowledge accumulated by mankind forces us to look for other approaches to organize the learning process. The use of modern technologies in the educational process creates favorable conditions for the formation of the personality of students and meets the needs of modern society.

\section{Methodology}

The methodological basis of the study was a conceptual approach and an appeal to the origins of informatization of modern educational space. In the course of the research, a pedagogical experiment aimed at dialectical analysis of trends and contradictions in the use of info-communication technologies in the educational process was carried out. The effectiveness of the process of informatization of the modern educational space of higher education was proved from the position of a conscious approach. 
Aleksandrova, 2021. Informatization of the Modern Educational Space of Higher Education from the Position of the Conscious Approach

In the course of the research, selective processing and analysis of empirical material, the method of observation, comparison and continuous sampling of the obtained data were being used. Structural and typological analysis of the found material, statistical methods of processing the obtained results were also reflected in the course of the conducted research.

\section{Research Results}

There are four stages of information revolutions in the history of mankind. During these revolutions not only the methods of information processing, but also lifestyle, value systems, methods of production have been changed. Having analyzed this fact the author concludes that at the moment, our society is no longer just informational, but information-conscious. By referring to the sphere of higher education, an informative-conscious approach is being emphasized. To substantiate this conclusion, we have to characterize the main stages in the history of human development (Bell, 1986; Dahrendorf, 1987; Toffler, 2002).

The first stage (4000 -3000 BC) is associated with the invention of writing. Knowledge has become possible to record and transmit from generation to generation through fixation in signs. The second stage is associated with the invention and spread of printing in the 15th century. Replication of knowledge has increased access to information for the people at large. The third stage (late 19th early 20th centuries) is associated with the invention of electricity. By appearing the telegraph, telephone, radio and television it became possible to transmit and accumulate information quickly and in any volume.

The fourth stage (70s of the 20th century) is associated with the invention of microprocessor technology and personal computers. This latest revolution gave impetus to human civilization for the transition from an industrial to an information society (Bell, 1986; Dahrendorf, 1994; Toffler, 2002).

In the era of the development of the human civilization and scientific and technological development, modern civilization reached its peak in political systems, in the forms of economic life, in the system of law. The only area where progress continues to take place is science and technology (Fukuyama, 1990). We can't agree with this statement, since the volume of new knowledge in the last century has been growing exponentially. In order not to get lost in the flow of information, quickly find it and use it correctly, there is a whole area of activity - IT technologies. This area includes everything related to information, its search, storage, processing, transmission.

Information technologies are often understood as hardware and software for the implementation of information processes. The author gives the following definition of this concept: Information technologies are the processes based on the ability to collect, handle and transfer information in order to obtain a new 
information product.

It is necessary to change the concept of the educational process, into which these technologies would organically fit in as a new teaching tool. The conditions created with their help should contribute to the formation of holistic thinking and worldview of the students, orient them towards the search for systemic connections and patterns. They must contribute to the disclosure, preservation and development of individual students' abilities, to the personal growth and to the constant dynamic updating of the content, forms and methods of the learning process.

In the concept of informatization (Concept of informatization of the sphere of education in the Russian Federation, 1998) is noted that the change in the content of education is possible in several directions:

a) the formation of academic disciplines that provide general education and professional training of students in the field of computer science;

b) the expansion of the use of informatization means that entail a change in the content of all academic disciplines at all educational levels;

c) the modeling of qualitatively new learning goals in the direction of training members of the "future information society", for which the ability to human communications, active mastery of the scientific picture of the world, flexible change in their work's functions and creative thinking will become an obvious vital necessity.

The author in this research is speaking about the transition to such a "future information society", using the term informative-conscious in the field of higher education. The study of the information environment took place in various aspects, among which three main ones can be distinguished:

1. Information environment as an activity. In this case a person is a participant in the communication process, the focus is on his ability to present personal knowledge in the form in which it can be transmitted. Having perceived the information the person is ready to turn it again into his personal knowledge.

2. Information environment as a system of historically established forms of communication.

3. Information environment as an information infrastructure created by a society to carry out communication activities on a scale corresponding to the level of the development of this society.

The education system as a whole and in each individual educational institution can be understood and described as an information educational environment or space. One of the main features of educational information environments is their systemic nature. The formation of the educational information environment involves: the teacher, the teaching staff of an educational institution, the state as a public institution. The teacher determines the 
Aleksandrova, 2021. Informatization of the Modern Educational Space of Higher Education from the Position of the Conscious Approach

content of the course program, the choice of educational literature, teaching methods, communication style. The teaching staff establishes the general requirements for students, the traditions of this educational institution, the form of relations between the teaching staff and students. The state determines the material support of education as a whole, the social order for the formation of a particular system of knowledge and views.

Summarizing all that has been said, let us give an author's definition to the concepts of information educational environment and information space.

Information educational environment is a set of conditions necessary for the development of the information space in which the educational activities of the subject are carried out.

Information space is the reality in which the subject exists and all information phenomena surrounding him.

It cannot be denied that info-communication technologies are undoubtedly the most important factor in the formation of the 21st century society. What just recently seemed like a miracle of technology turns out to be quite a common sphere of consumption. Students are ready to use network technologies quite consciously, on an intuitive level. Software has evolved into an intelligent support environment that guides user actions. It is very important to note that information technologies act precisely in the role of intellectual support, and not as a replacement for human intelligence or its component. The global communication network makes the student and the teacher of the 21st century an informatively conscious owner of information.

In Russia the historical transition was due to the origins and development of higher education; trends in the development of the education system and the formation of an unified educational space; the functioning and development of society; the constitutional right guarantee to get higher education; the transition to a modular structure of professional training in the higher education system; the active development of high-information technologies; the definition of uniform standards for previously various systems.

The implementation of the approach, proposed by the author, is aimed at:

- $\quad$ solving the problems of interaction between the education sector and the IT industry;

- $\quad$ analysis of the formation of new didactic paradigms;

- determining the role of information technologies in the educational process;

- $\quad$ building of a competitive specialists in the higher education system;

- considering the information environment as a component of the educational and pedagogical management system. 


\section{Conclusions}

Information technologies occupy a unique position in modern society. Unlike other scientific and technological advances, means of computer technology and informatics are used in almost all areas of human intellectual activity, contributing to progress in technology and technics. They are intelligent components of technologies for the design, production and management of complex processes and structures. The global communication network is steadily expanding, it acquires ever-growing importance and new functions. It is increasingly being used not only to search for information and communication, but also to educate, to get information in other areas, marking the beginning of the formation of a global network community.

In the field of research aimed at the socio-philosophical analysis of the foundations of pedagogical activity and education, a close dependence of the development of education on the development of informatization of modern society was revealed and an informative-conscious approach in the system of higher education was showed up. This approach is based on the sphere of informatization and info-communication technologies, and has an informative essence in its foundation.

Detailed conclusions were included in numerous author's publications (Aleksandrova \& Aleksandrov, 2013; Aleksandrova, 2015; Aleksandrova \& Aleksandrov, 2018; Aleksandrova, 2020) which clearly indicate that the analysis of the relationship between the development of society and the use of modern information and communication technologies in education allows us to highlight the informative-conscious approach as an independent and reasonable one. Therefore, the informative-conscious approach, put forward by the author, leads to a fundamentally new educational environment that can ensure the provision of high-quality educational services based on information and communication educational technologies.

In the studies have been performed statistical calculations confirming the hypotheses that show us the strength of relationships between individual independent and dependent variables. All hypotheses have been accepted as true. All thorough analysis of the topic has been included in the published scientific monography (Aleksandrova, 2016).

Summing up, we conclude, that the higher education is becoming the most important mechanism for the reproduction of science and technology, and ultimately of the entire modern post-industrial civilization. The implementation of the paradigm of classical education - info-communication technologies of education from the standpoint of a conscious approach reveal the essence of the transition to a global information society and 
Aleksandrova, 2021. Informatization of the Modern Educational Space of Higher Education from the Position of the Conscious Approach

the allocation of an informative-conscious approach in the higher education system as innovative and independent.

\section{References}

Aleksandrova, E.V. \& Aleksandrov, E.V. (2013). The use of information and communication technologies in the process of improving the quality of education. Education and Society, 6 (83), 46-49.

Aleksandrova, E.V. (2015). Philosophical understanding of the informatization trends in the modern educational space. Philosophy of education, 5 (62), 26-34.

Aleksandrova, E. V. (2016). Informative-conscious approach in the system of higher education: sources, essence, perspectives: monograph. Samara: SamGUPS.

Aleksandrova, E.V. \& Aleksandrov, E.V. (2018). Features of the development of multimedia manuals within the disciplines of the humanities and technical cycles for students of railway specialties. Azimuth of Scientific Research: Pedagogy and Psychology, 3(24), 13-16.

Aleksandrova, E.V. (2020). Technologization of modern foreign language education. The scientific heritage, 50 , 32-34.

Bell, D. (1986). Social framework of the information society / / New technocratic wave in the West. - Moscow: Progress.

Babansky, Yu. K. (1989). Selected pedagogical works / Acad. Ped. Sciences of the USSR. - M.: Pedagogika.

Chernov, A. A. (2003). Formation of the global information society: Problems and prospects. M.: Publishing and trading Corporation "Dashkov and K".

Dahrendorf, R. (1994). Der moderne soziale Konflikt. Essay zur Politik der Freiheit - Moscow: ROSSPEN.

Fukuyama, F. (1990). The end of history. Questions of philosophy, 3, 84-118.

Latyshev, V. A. (1995). Training technologies: formation and development: textbook. Moscow: MAI Publishing House.

Melamud, V. E. (2004). Informatization of education as a condition for its modernization. Moscow: Moscow Psychological and Social Institute.

Prauzner, T (2020). Innovativeness of didactic practice in the field of current pedagogical knowledge. Society. Integration. Education. Proceedings of the International Scientific Conference, Volume II, 247-255.

Shrader, Yu. A. (1976). Information resources and information environment // Scientific and technical information (Moscow), 1, 3-6.

Shutenko, E. N. \& Derevyanko, Yu. P. (2016). Personocentric construction of information technologies in the system of university training. Electronic scientific journal "Modern problems of Science and Education". Retrieved from https://scienceeducation.ru/pdf/2015/5/449.pdf

The concept of informatization of the sphere of education in the Russian Federation. (1998). Moscow: VNIISI.

Toffler, E. (2002). The third wave. - Moscow: AST Publishing House.

Velichko, V. V. (2009). Basics of info-communication technologies. - Moscow: Hot lineTelecom. 